\title{
El sentido olvidado del patriotismo republicano *
}

\author{
MAURIZIO VIROLI \\ Princeton University
}

REsumen. En este artículo Maurizio Viroli muestra que aunque el patriotismo republicano tiene una dimensión cultural es, sobre todo, una pasión política basada en la experiencia de la ciudadanía. Patriotismo es el amor por una república libre y por su forma de vida: il vivere libero. En este sentido, el patriotismo es casi lo opuesto al nacionalismo. Para los nacionalistas el patriotismo es el amor por una libertad más modesta: la libertad de disfrutar a la sombra del trono, y en paz, de la casita y el majuelo. Para los patriotas republicanos el amor por la patria es una pasión artificial, para los nacionalistas es natural. Como conclusión, Viroli sugiere que el patriotismo republicano es capaz de responder a los dilemas de la democracia moderna al ir más allá de la elección entre el mito del nacionalismo cívico y el horror del nacionalismo étnico.
Abstract. In this article Maurizio Viroli shows that although republican patriotism has a cultural dimension it is primarily a political passion based upon the experiencia of citizenship. Patriotism is the love for a free republic and for its way of life: il vivere libero. In this sense republican patriotism is almost the contrary of nationalism. For nationalists patriotism is the love for a modest liberty: the freedom to enjoy in the shadow of the throne one's dwelling and vineyard in peace. For republican patriots love of country is an artificial passion, for nationalists it is a natural one. As a conclusion, Viroli suggest that republican patriotism is able to answer the dylemas of modern democracy beyond the choice between the myth of civic nationalism and the horror of ethnic nationalism.

Uno de los aspectos que encuentro más llamativo del debate contemporáneo sobre el patriotismo, el nacionalismo y el cosmopolitismo es que nadie parece tomarse la molestia de especificar lo que querían decir los filósofos, historiadores, poetas, agitadores y profetas pertenecientes a la familia republicana, durante los dos últimos milenios, cuando hablaban de amor a la patria ${ }^{1}$.

* Este trabajo junto a los de Michael Walzer, Ángel Rivero, Margaret Canovan, Ronald Beiner y Andrew Dobson fueron presentados, en una primera versión, en la IV Sesión del Programa «Europa Mundi», celebrado en Santiago de Compostela en mayo de 2000 y cuyo coordinador general fue Ramón Maíz, oficiando como coordinador de la sesión Rafael del Águila.

Traducción de Ángel Rivero.

${ }^{1}$ El mejor ejemplo son los artículos publicados en Cohen (1996). 


\section{Rasgos generales del patriotismo republicano}

Para los teóricos republicanos clásicos, y sobre todo para los romanos, el amor de la patria es una pasión. De forma más precisa: se trata de un amor generoso y compasivo por la república (caritas reipublicae) y por sus ciudadanos (caritas civium). Como dijo con posterioridad un pensador escolástico, Tolomeo de Lucca: «Amor patriae in radice charitatis fundatur». Esto es, «el amor a la patria encuentra su fundamento en la raíz de la caridad que antepone, no las cosas privadas a las comunes, sino aquello que es común a lo privado» ${ }^{2}$.

Hasta cuando el amor por la patria respeta los principios de la justicia y de la razón, y, por tanto, es denominado amor racional («amor rationalis»), tal como dijo Remigio de Girolami, se trata del afecto por una república particular y por unos ciudadanos particulares que nos son queridos porque compartimos con ellos cosas importantes: las leyes, la libertad, el foro, el senado, las plazas públicas, los amigos, los enemigos, la memoria de las victorias y el recuerdo de las derrotas, las esperanzas, los miedos. Es una pasión que crece entre ciudadanos iguales y no el resultado del consentimiento racional otorgado a los principios políticos de la república en general. Puesto que es una pasión se traduce en acción, y de forma más precisa, en actos de servicio al bien común (officium) y de cuidado (cultus) ${ }^{3}$.

Por último, debe tenerse en cuenta que para los teóricos republicanos la caritas reipublicae es una pasión revitalizadora que impele a los ciudadanos a ejercer los deberes de la ciudadanía y que proporciona a los gobernantes la fuerza precisa para acometer las duras tareas necesarias para la defensa, o la institución, de la libertad. Como explica Tito Livio en el Libro II, sección 2, de su Historia, cuando cuenta las primeras etapas de la consolidación de la libertad romana tras la expulsión de Tarquino el Soberbio, fue la caridad hacia la república (caritas reipublicae) la que dio a Bruto la fuerza moral para superar su rechazo y acometer la desagradable tarea de hablar contra Lucio Tarquino ante el pueblo de Roma.

Como demuestra el párrafo del De regimene principium escrito por Tolomeo de Lucca que he citado, componentes muy importantes del lenguaje republicano del patriotismo se transmitieron a los tratados sobre el gobierno de los escritores políticos escolásticos y, lo que es más importante, a los sermones que se pronunciaban en las iglesias de Florencia y de otras ciudades libres italianas. Este matrimonio entre el lenguaje romano del patriotismo y el patriotismo cristiano posibilitado por la palabra central caritas, ilumina las raíces del patriotismo florentino de los siglos XIV y XV. Este patriotismo era ferozmente anticlerical, como lo señala el dicho «amar a la a patria más que al propio alma», pero también profundamente cristiano. Este contexto intelectual nos permite enten-

\footnotetext{
${ }^{2}$ Tolomeo de Lucca (1954), p. 299.

${ }^{3}$ Proporciono referencias textuales en Viroli (1995).
} 
der el significado de las palabras de Maquiavelo en Discorsi, II.2, cuando, tras desplegar una crítica devastadora de la religión cristiana y de la educación cristiana, observa que «aunque parece que se ha afeminado el mundo y desarmado el cielo, esto procede sin duda de la vileza de los hombres, que han interpretado nuestra religión según el ocio, y no según la virtud. Porque si se dieran cuenta de que ella permite la exaltación y la defensa de la patria, verían que quiere que la amemos y la honremos y nos dispongamos a ser tales que podamos defenderla ${ }^{4}$. Por tanto, también Maquiavelo escuchó un lenguaje del patriotismo que combinaba la caritas romana y la cristiana, a pesar de que las obras de los pensadores escolásticos no fueran sus lecturas favoritas ni las iglesias su paradero preferido.

Un uso parecido del lenguaje del patriotismo entendido como caritas aparece en la obra de John Milton Defense of the People of England, de 1651 (vol. VII, p. 455), donde escribe que la ejecución de Carlos I fue un acto no de inspiración facciosa, o un deseo de usurpar los derechos de otros, mera disputa o deseos perversos, o furia, o locura, sino amor a la patria — «patriae caritas»— como dice la versión latina.

Para los teóricos republicanos la república es un ordenamiento político y una forma de vida. Esto es, una cultura. Para describir el amor del pueblo por sus instituciones republicanas y por la forma de vida basada en ellas, Maquiavelo habla, por ejemplo, de amor al «vivere libero». Otros republicanos de su tiempo definieron la república como «un tipo de forma de vida de la ciudad» («una certa vita della città», Brucioli, 1982, p. 112).

Desde luego, el patriotismo republicano tiene una dimensión cultural, pero es primariamente una pasión política basada en la experiencia de la ciudadanía, no en elementos prepolíticos comunes derivados del haber nacido en el mismo territorio, pertenecer a la misma raza, hablar la misma lengua, adorar a los mismos dioses o tener las mismas costumbres. Significa esto que el argumento de que el patriotismo republicano no es una respuesta intelectual válida para las cuestiones contemporáneas de la ciudadanía democrática porque «un credo político es insuficiente» ${ }^{5}$, está completamente equivocado, ya que el patriotismo republicano no descansa en un credo puramente político.

Los autores latinos tenían muy clara la distinción entre los valores políticos y los valores culturales de la república y los valores no políticos de la nacionalidad. De hecho, utilizaban dos palabras diferentes: patria y nati ${ }^{6}$. Cuál de las dos se consideraba más importante resulta bastante obvio. Los lazos de la ciudadanía, como dijo Cicerón en De Officiis (I.17.53) son más próximos y más dignos que los lazos de la natio.

Esta distinción y esta jerarquía fueron reiteradas por los teóricos posteriores. En la Encyclopédie (vol. XII, p. 178), por ejemplo, leemos que Patrie, no significa

\footnotetext{
${ }^{4}$ Maquiavelo (1987), pp. 188-189.

${ }^{5}$ Smith (1996), p. 22.

${ }^{6}$ Véase, por ejemplo, Quintiliano, Institutio oratoria, vol. 10, pp. 24-25.
} 
el lugar en el que hemos nacido, como cree la concepción vulgar. Por el contrario, significa «estado libre» (état libre) del que somos miembros y cuyas leyes protegen nuestra libertad y nuestra felicidad (notre liberté et notre bonheur).

Para el autor de la entrada, el término patrie es sinónimo de república y libertad, como lo era para Maquiavelo y para los escritores políticos republicanos. Bajo el yugo del despotismo no hay patrie, por la razón muy obvia de que bajo el gobierno despótico los súbditos carecen de protección y están excluidos, precisamente como si fueran extranjeros (ibid.). Siguiendo los pasos de Montesquieu, el autor observa que «aquellos que viven bajo el despotismo oriental, donde no se conoce otra ley que los gustos del soberano, otra máxima que la adoración de sus caprichos, otro principio de gobierno que el terror, donde nadie ni ninguna fortuna está a salvo, no tienen una patrie y ni siquiera conocen su nombre, que es expresión verdadera de felicidad ${ }^{7}$.

Esto significa que el lugar común de que la Ilustración era antipatriótica es un error de bulto. Los philosophes no eran nacionalistas, pero desde luego eran patriotas en el sentido del patriotismo republicano. Y para ellos, ser patriotas significaba sentir la caritas reipublicae. Como dijo Jean-Jacques Rousseau, un distinguido miembro de la familia republicana: «No son los muros, ni los hombres los que hacen la patria, sino las leyes, los usos, las costumbres, el gobierno, la constitución, y aquello que resulta de todo esto. La patria se forma en las relaciones entre el Estado y sus miembros; cuando esas relaciones cambian o se disuelven, desaparece la patria ${ }^{8}$.

Es la experiencia de la libertad republicana, o la memoria o la esperanza de la misma, lo que hace que tenga sentido la ciudad. Los teóricos republicanos eran perfectamente conscientes de que el tipo de comunalidad generada por el hecho de vivir en la misma ciudad, o la misma nación, o de hablar la misma lengua, y de adorar los mismos dioses no era suficiente para generar el patriotismo republicano en el corazón de los ciudadanos: una patria verdadera, afirmaban, sólo puede ser una república libre.

Afirmaban también que el amor a la patria no es en absoluto un sentimiento natural, sino una pasión que necesita ser estimulada a través de la legislación o, de forma más precisa, a través del buen gobierno y de la participación de los ciudadanos en la vida pública. Rousseau expresó con elocuencia esta idea en su Economie politique: «Que la patrie se montre donc la mere commune des citoyens, que les avantages dont ils jouissent dans leur pays le leur chere, que le gouvernement leur laisse assez de part á la l'administration publique

Ibid, p. 180. «Ceux qui vivent sous le despotismo oriental, où l'on en connait d'outre loi que la volonté du souverain, d'autres maximes que l'adoration de ses caprices, d'autres principes de gouvernement que la terreur, où aucune fortune, aucune tête n'est en sureté; ceux là, n'ont point de patrie, et nén connoissent pas même le mot, qui est la véritable expression du bonheur».

${ }^{8}$ Rousseau (1965), vol. 19, p. 190. «Ce en sont pas les murs, ni les hommes qui font la patrie. Ce sont les lois, les moeurs, les coutumes, le gouvernement, la constitution, la manière d'etre qui resulte de tout cela. La patrie est dans les rélations de l'état à ses membres; quand ces rélations changent ou s'aneantissent, la patrie s'évanouit». 
pur sentir qu'il son chez eux et que les lois en soient a leur yeux que les garants de la commune liberté» ${ }^{9}$.

Pocos años después, Gaetano Filangieri refinó el pensamiento de Rousseau en La Scienza della Legislazione: «Non abusiamo del sacro nome di amore della patria, per indicare quell'affezione pel patrio suolo ch'è una appendice de'mali istessi delle civili unioni, e che si può ritrovare cosí nella più corrotta, come nella più perfetta società». Afirma que el verdadero amore della patria es una pasión artificial «essa può essere dominante de ignota; essa può esser senza alcun vigore in un popolo, e può esser onnipotente in un altro. La sapienza delle leggi e del governo la introducono, la stabiliscono, l'espandono, l'invigoriscono; i vizii dell'uno e delle altre la indeboliscono, l'escludono, la proscrivono» ${ }^{10}$.

Otro jurista eminente, Gian Domenico Romagnosi, llegó a afirmar que el verdadero patriotismo es la consecuencia del buen gobierno y de la participación política: «Il vero patriottismo è nel municipio. La molla, solida, attiva, reale e permanente del vero e sicuro patriottismo sta nel Municipio, e oso dire che non può stare che in lui solo. Aggiungo di più: che in lui solo sta la base di sicurezza di totto e l'ordinamento politico di uno stato civile» ${ }^{11}$. Es más, Carlo Cattaneo todavía es más claro y definió la comuna de forma mejor: «las comunas son la nación en el refugio esencial de su libertad» («I comuni sono la nazione; sono la nazione nel più intimo asilo della sua libertà» ${ }^{12}$ ).

\section{El patriotismo republicano y el nacionalismo}

Ha de resultar ahora bastante fácil identificar la diferencia entre el patriotismo republicano y el nacionalismo. Si por nacionalismo entendemos lo que los fundadores del lenguaje del nacionalismo entendían, me parece claro que los patriotas republicanos y los nacionalistas están en desacuerdo sobre la cuestión central de qué es una verdadera patria. De hecho, los teóricos del nacionalismo de finales del siglo XVIII comenzaron, en su intento por construir un lenguaje nuevo del nacionalismo, por atacar el principio republicano de que sólo una república que se autogobierne es una verdadera patria.

En fecha tan temprana como 1761, Thomas Abbt imprimió un panfleto de éxito titulado Muerte de la patria, para poner en solfa la idea de que el amor a la patria sólo florece en las repúblicas. Así, una monarquía puede ser una patria si todos, incluido el monarca, se someten a las leyes que alimentan el bien común. No hay diferencia entre el súbdito de una monarquía y el ciudadano de la más libre de las repúblicas: están igualmente sujetos a las

${ }^{9}$ Rousseau, Economie politique, Oeuvres Complètes, III, p. 258.

${ }^{10}$ Filangieri, La Scienza della Legislazione, IV, parte 2, p. 42.

${ }^{11}$ Romagnosi, «Istituzioni di civile filosofia», en Opere, a cargo de Alessandro de Giorgi, Milán, Perelli e Mariani, poi Volpato, 1841-1848, vol. III, p. 1548.

${ }^{12}$ Cattaneo, «Sulla legge comunale e provinciale». 
leyes. Ninguno es libre, pero todos son libres de acuerdo con el espíritu de la constitución del Estado ${ }^{13}$. En una buena monarquía todos son «ciudadanos» («Bürger») al margen de sus distintos rangos sociales y su bien es unísono con el bien de la patria ${ }^{14}$. Una monarquía, concluye Abbt, también puede ser una patria que podemos amar; y si podemos amarla, hemos de amarla («wir es lieben müssen») ${ }^{15}$.

Este argumento fue reafirmado y amplificado con vigor por Johann Gottfried Herder. Tal como observó en uno de sus primeros escritos - iTenemos aún el Publico y la Patria de antaño? - la patria todavía significa libertad pero ya no la libertad de los antiguos.

El patriotismo moderno ya no precisa de la fuerza espiritual que los antiguos consideraban necesaria para resistir a los enemigos de la libertad. Se trata de un sentido más ordinario del deber y de un compromiso con una «libertad más modesta» que un Emperador puede garantizar mejor que una república:

«En nuestros días todos los estados se han acomodado a un sistema de equilibrio. Aquel que no puede protegerse a sí mismo necesita un patrón, un padre. Nuestro pueblo ya no se caracteriza por la audacia desvergonzada de los antiguos. Prevalece en él, en su lugar, una libertad más refinada, más modesta: la libertad de conciencia, ser un hombre honesto y un cristiano, la libertad de disfrutar a la sombra del trono de su casita y su majuelo, en paz y tranquilidad, y ser dueño de los frutos del propio trabajo; la libertad de tener en sus propias manos su felicidad y su comodidad, de ser el amigo de sus íntimos y el padre y guardián de sus hijos ${ }^{16}$.

Herder señala al Zar Pedro el Grande como un «verdadero patriota», que se ha convertido «en el padre de su vieja patria en el creador de una nueva patria» ${ }^{17}$. El patriotismo le proporcionó la inspiración para emancipar a sus súbditos, contra su voluntad, de la servidumbre, y la determinación para enfrentarse a la fortuna adversa. Falta de ciudadanos, la patria puede contar con un padre: el gran patriotismo del Emperador y el patriotismo común de los súbditos son suficientes para conservar la «modesta libertad» que ansían los hombres modernos.

Aunque los hombres modernos no poseen el intenso patriotismo político de los antiguos, un monarca patriota puede exigirles el mismo grado de auto-

\footnotetext{
${ }^{13}$ Abbt, Vom Tode für das Vaterland, p. 16.

${ }^{14}$ «Sind wir nicht verbunden unsere Wohlfart zu berforden sie sicher zu gründen? Und diese Wohlfart ist so genau mit der Wohlfart des Vaterlandes, das heist, mit der Ausrechthaltung der Gesetze, deren Schuss ich geniesse, verbunden!», Vom Tode für das Vaterland, p. 18.

${ }^{15}$ Abbt, Vom Tode für das Vaterland, p. 18.

${ }^{16}$ Johann Gottfried Herder, «Haben wir nocht jetz das Publikum Und Vaterland der Alten?», en Ulrich Gaier (ed.), Johann Gottfried Herder Frühe Schriften 1764-1772, p. 61.

17 «War Peter der Grosse nicht ein wahrer Patriot, da er, als der Name Und das Wunder unsers Jahrunderts, der Vater seines Alten, Und der Schöpfer eines neues Vaterlandes wurde?», en Johann Gottfried Herder, Haben wir noch jetz das Publikum Und Vaterland der Alten?, in Ulrich Gaier (ed.), Johann Gottfried Herder Frühe Schriften 1764-1772, p. 62.
} 
sacrificio que se dice que las repúblicas son capaces de excitar en sus ciudadanos. Las palabras «patria, monarca, emperatriz», escribe Herder, sonarán a todo hombre que no sea un insensible mercenario como «el sonido de la victoria que estimula sus venas, excita su corazón, moviliza sus manos y le hace proteger su pecho con armadura de acero» ${ }^{18}$. Morir por la patria es dulce y honorable, y no importa si en la patria «gobiernan cien y la ley» o si «gobierna uno y la ley», siempre que el gobernante sea el padre o la madre de un pueblo feliz.

Los patriotas republicanos y los nacionalistas también están en desacuerdo sobre lo que sea o deba ser el amor por la patria. Los primeros consideran el amor a la patria como una pasión artificial que ha de ser introducida y reproducida, de forma constante, por medios políticos. Para los últimos se trata de un sentimiento natural que ha de protegerse de la contaminación cultural y de la asimilación cultural. Su diversa interpretación del amor por la patria es consecuencia de su diferente concepción de la patria y de la nación respectivamente. La patria de los republicanos es una institución moral y política. La nación de Herder es una creación natural. Éste considera las nacionalidades no como producto de los hombres, sino como la obra de una fuerza viva, orgánica, que anima el universo. Las repúblicas se originaron debido a la virtud extraordinaria y a la sabiduría de sus legendarios fundadores. Las naciones las hizo el mismo Dios, en tanto fuerza viva que modela unidades orgánicas nacionales sobre el caos de la materia homogénea y reflejan, por tanto, los planes y la voluntad eterna de Dios.

Cuando Herder subraya que la naturaleza ha creado nacionalidades pero no estados, quiere decir que las primeras ocupan una posición superior a los últimos. Para los republicanos la pérdida de la república es la mayor tragedia. Para Herder aún es más trágica la pérdida de la propia nación: privad a un hombre de su país (en el sentido de nacionalidad), escribió, «y le habréis despojado de todo» ${ }^{19}$.

Esto no quiere decir que la idea de nación se haya utilizado siempre contra el patriotismo republicano o para sostener proyectos nacionalistas. El ejemplo más obvio es la definición del principio de nacionalidad de John Stuart Mill en su $A$ System of Logic:

«No hace falta decir que no entendemos (el principio de nacionalidad) como infundada antipatía por los extranjeros; o por el cultivo de peculiaridades absurdas porque son nacionales; o por el rechazo a adoptar lo que otros países han descubierto que es bueno. En todos estos sentidos, las naciones que tienen el espíritu nacional más fuerte son las que tienen menos nacionalidad. Lo entendemos como un principio de simpatía, no de hostilidad; de unión, no de separación. Nos referimos a un sentimiento de interés común entre todos

\footnotetext{
${ }^{18}$ Johann Gottfried Herder, Haben wir noch jetz das Publikum Und Vaterland der Alten? en Ulrich Gaier (ed.), Johann Gottfried Herder Frühe Schriften 1764-1772, pp. 50-60.

${ }^{19}$ Sämmtliche Werke, XIII, pp. 261-262.
} 
aquellos que viven bajo el mismo gobierno y que están contenidos en unas mismas fronteras naturales o históricas. Hacemos referencia a que una parte de la comunidad no ha de considerarse forastera frente a otra parte; a que han de cultivar el lazo que les mantiene juntos; han de sentir que son un pueblo, que su suerte está unida, que lo que sea malo para un compatriota es malo para ellos mismos; y que no pueden, de forma egoísta, desentenderse de su participación en los problemas comunes cortando la conexión» ${ }^{20}$.

Esta concepción de la nación es equivalente a aquello que Mazzini entendía por patria:

«Una patria es un asociación de hombres libres e iguales unidos en el fraternal acuerdo de trabajar por un fin único. (...) Una patria no es una agregación, es una asociación. No hay patria verdadera sin derecho uniforme. No hay patria verdadera donde la uniformidad del derecho es violada por la existencia de castas o privilegios» ${ }^{21}$.

Otro ejemplo del principio de nacionalidad interpretado como equivalente a la idea republicana clásica de patria puede verse en Carlo Pisacane. El principio de nacionalidad que ha excitado a las almas más generosas en 1848, escribió en 1860, era un ideal de libertad. Nacionalidad significa la libre expresión de la voluntad colectiva de un pueblo, de un interés común, de total y absoluta libertad, sin clases, grupos o dinastías privilegiadas. El amor por la patria sólo puede crecer en el suelo de la libertad, y sólo la libertad puede convertir a los ciudadanos en defensores de la república. Bajo el yugo de príncipes y monarcas, las pasiones del patriotismo están condenadas a degenerar ${ }^{22}$.

$\mathrm{Al}$ igual que Mazzini, Pisacane interpreta el principio de nacionalidad como lo opuesto al nacionalismo. En la Europa de las monarquías, escribió, el «principio de nacionalidad» se ha corrompido en «mediocre nacionalismo»; la política de la fuerza bruta y del interés ha sustituido a la política del libre y espontáneo desarrollo de las naciones ${ }^{23}$.

Por tanto, la diferencia entre el patriotismo republicano y el nacionalismo es bastante grande. Igualmente grande es la diferencia entre el patriotismo republicano y el nacionalismo cívico, por una parte, y el patriotismo republicano

\footnotetext{
${ }^{20}$ John Stuart Mill, $A$ System of Logic, VI, 10.5.

${ }^{21}$ G. Mazzini, «Dei doveri dell'uomo», en Scritti politici, Terenzio Grandi y Augusto Comba (eds.), Turín, UTET, 1972, p. 884.

22 «Per esservi nazionalità bisogna che non frappongasi ostacolo di sorta alla libera manifestazione della volontà collettiva, e che veruno interesse prevalga all'interesse universale, quindi non può scompagnarsi dalla piena e assoluta libertà, né ammettere classi privilegiate, o dinastie, o individui la cui volontà, attesi gli ordini sociali, debba assolutamente prevalere: é nazionalità quella che godesi sotto il giogo d'un assoluto sovrano?», en Carlo Pisacane, «La Rivoluzione», en Franco della Peruta, Scrittori politici dell'Ottocento, I, Milán-Nápoles s.d., p. 1181. Véase también la p. 1184: "Col dispotismo non v'è nazionalità, qualunque lingua parli Il tiranno, qualunque sia Il luogo dove ebbe i natali».

${ }^{23}$ Mazzini's Letters, p. 169.
} 
y el nacionalismo étnico, por otra. El patriotismo republicano difiere del nacionalismo cívico en que es una pasión y no el resultado del consentimiento racional. No se trata de lealtad a principios políticos universales neutrales tanto histórica como culturalmente, sino de compromiso con las leyes, la constitución y la forma de vida de una república particular. El patriotismo republicano es también diferente del nacionalismo étnico porque no concede relevancia moral o política a la etnicidad. Por el contrario, reconoce relevancia moral y política, y belleza, a los valores políticos de la ciudadanía, particularmente la igualdad republicana, que son hostiles al etnocentrismo.

También quiero subrayar que encuentro la interpretación republicana del patriotismo más convincente que el punto de vista contemporáneo, según el cual, para mantener unidos pueblos heterogéneos, necesitamos «mejores alforjas» que los valores culturales y políticos de la república, tal como ha señalado recientemente Anthony Smith. No sé qué quiere decir Smith cuando habla de «mantener unidos», pero si se refiere, como yo, a mantener juntos a individuos libres e iguales, no necesitamos otra cosa que políticas inspiradas por los ideales de la libertad republicana y de la igualdad republicana, y una cultura basada en tales ideales. La ciudadanía no nace de los lazos de la nacionalidad. Los pueblos más homogéneos cultural, religiosa o étnicamente no son los que tienen mayor espíritu cívico. Por el contrario, tienden a ser intolerantes, prejuiciosos y aburridos. La política, la verdadera política democrática, se basta para construir la ciudadanía. No necesita de ayudantes incómodos.

El que esto sea un proyecto político deseable o posible es otra cosa. En otro lugar he argumentado que sí lo es. Aquí sólo quiero sugerir que no estamos abocados en absoluto a la elección entre el mito del nacionalismo cívico y el horror del nacionalismo étnico.

\section{BIBLIOGRAFÍA}

Аввт, Thomas (1761): Vom Tode für das Vaterland.

Brucioli, Antonio (1982): Dialogi, A. Landi (ed.), Nápoles-Chicago.

Cohen, Joshua (ed.) (1996): For Love of Country, Boston, The Beacon Press.

D'Alembert y Diderot (1765): Encyclopédie, Neuchatel.

FilAngIeri, Gaetano: La Scienza della Legislazione.

Ginzburg, Natalia (1984): «Prefacio», en G. Falaschi (ed.): La letteratura partigiana in Italia 1943-1945, Roma, Editori Riuniti.

Herder, Johann Gottfried: «Haben wir noch jetz das Publikum Und Vaterland der Alten?», en Ulrich Gaier (ed.): Johann Gottfried Herder Frühe Schriften 1764-1772. - Sämmtliche Werke.

Maquiavelo, Nicolás (1987): Discursos sobre la primera década de Tito Livio, Madrid, Alianza Editorial.

Mazzini, Giuseppe (1972): «Dei doveri dell'uomo», en Scritti politici, Terenzio Grandi y Augusto Comba (eds.), Turín, UTET.

MiLl, John Stuart: A System of Logic. 
Milton, John (1932): «Defense of the People of England», en The Works of John Milton, vol. VII, Nueva York, Columbia University Press.

Pisacane, Carlo (s.d.): «La Rivoluzione», en Franco della Peruta (ed.): Scrittori politici dell'Ottocento, I, Milán-Nápoles.

Robespierre, Maximilien (1965): Discours et Rapports à la Convention, Bouloiseau (ed.), París, Union Générale d'Edition.

Romagnosi, Gian Domenico (1841-1848): «Istituzioni di civile filosofia», en Alessandro de Giorgi (ed.): Opere, Milán, Perelli e Mariani poi Volpato.

Rousseau, Jean-Jacques (1965): Correspondance complète de Jean-Jacques Rousseau, R. A. Leigh (ed.), vol. XIX, The Voltaire Foundation, Banbury, Oxfordshire.

- (1964): «Economie politique», en Oeuvres Complètes, vol. 3, París, Gallimard.

Shaftesbury, Anthony 3d Earl of. (1963): Characteristics of Men, Manners, Opinions, Times, Glouster, Mass., Peter Smith.

Smith, Anthony (1996): «In Search of (one-sided) Statues of Liberty», The Times Higher Education Supplement, 9 de agosto.

Tito Livio: Historias.

Tolomeo de Lucca (1954): «De Regimine Principum», en R. Spiazzi (ed.): Divi Thomae Aquinatis Opuscula Philosophice, Turín, 1954.

VIroli, Maurizio (1995): For Love of Country, Oxford, Oxford University Press. 